\title{
Antiulcerogenic Activity of 1-Hydroxy-3,7,8-trimethoxyxanthone Isolated from the Methanol Extract of Anthocleista vogelii PLANCH. in Rats
}

\author{
Gilbert Ateufack, ${ }^{1}$ Télesphore B. Nguelefack, ${ }^{1}$ Hippolyte K. Wabo, ${ }^{2}$ \\ Pierre Tane, ${ }^{2}$ and Albert Kamanyi ${ }^{1}$ \\ ${ }^{1}$ Laboratory of Animal Physiology and Phytopharmacology, Faculty of Science, University of Dschang, P.O. Box 67 Dschang, Cameroon \\ ${ }^{2}$ Laboratory of Natural Products, Faculty of Science, University of Dschang, P.O. Box 67 Dschang, Cameroon
}

Correspondence should be addressed to Gilbert Ateufack; ateufack2000@yahoo.fr

Received 27 April 2013; Revised 1 November 2013; Accepted 5 November 2013; Published 2 January 2014

Academic Editor: Gyula Mozsik

Copyright @ 2014 Gilbert Ateufack et al. This is an open access article distributed under the Creative Commons Attribution License, which permits unrestricted use, distribution, and reproduction in any medium, provided the original work is properly cited.

\begin{abstract}
Anthocleista vogelii (Loganiaceae) PLANCH. is used in Cameroonian ethnomedicine for the treatment of stomach ache and for curing fever and is used as purgative. Further investigations have shown that the stem bark of this plant possesses potent antiulcer properties. We have investigated the cytoprotective and antisecretory actions of 1-hydroxy-3,7,8-trimethoxyxanthone (AV), the xanthone obtained from the methanol extract of the stem bark. Oral administration of AV at the doses of 1,2, and $5 \mathrm{mg} / \mathrm{kg}$ prevented in a dose-dependent manner ulcers induced by $\mathrm{HCl} /$ ethanol (60.90 to $93.22 \%$ ), Indometacin (46.86 to 89.68\%), and pylorus ligation ( 0.00 to $70.69 \%)$. AV reduced pylorus-ligated gastric acid secretion from $134.17 \mathrm{mEq} / \mathrm{l}$ in the controls to $118.55,121.50$, and $96.93 \mathrm{mEq} / \mathrm{l}$, respectively, for the 1,2 , and $5 \mathrm{mg} / \mathrm{kg}$ doses and increased mucus secretion significantly in a dose-dependent manner in all experimental models. The cytoprotective and antisecretory properties of AV could thus be due to its ability to strengthen gastric mucosal defences through enhanced gastric mucus production.
\end{abstract}

\section{Introduction}

In Africa and some parts of Europe, gastric peptic ulcers represent $20 \%$ of all peptic ulcers [1]. Ulcer results from the imbalance between damaging factors within the lumen and protective mechanisms within the gastroduodenal mucosa [2]. It has been observed that many patients practice automedication using nonsteroidal anti-inflammatory drugs and other classes of drugs [3] that increase the incidence and the prevalence of this ailment.

A good number of drugs are now available for the treatment of peptic ulcer and these drugs are broadly classified into two main groups: those that offer cytoprotection by virtue of their effects on mucosal defensive factors and those that decrease or counter acid-pepsin secretion [4].

Reports on clinical evaluation of these drugs show that there are incidences of relapses and adverse effects and danger of drug interactions during ulcer therapy [4].
Hence, the search for antiulcer drugs continues and has also been extended to herbal drugs in order to find sources for new and cheaper novel molecules, which offer better protection and decrease the incidence of relapse.

We have demonstrated in previous works the antiulcer properties of the aqueous and methanol extracts of the stem bark of Anthocleista vogelii in rats [5]. This plant is a small tree, which grows in the tropical rain forest areas of West Africa [6]. In African traditional medicine, the stem bark and leaves are used as an anti-inflammatory and antidiabetic and also in the treatment of wounds $[6,7]$. Previous studies on this plant showed the presence of alkaloids, xanthones, secoiridoids, terpenes, and phthalides $[7,8]$. Complete prevention of lesion formation observed in the oral administration of a dose of $500 \mathrm{mg} / \mathrm{kg}$ in both $\mathrm{HCl} /$ ethanol and Indomethacin-induced gastric ulcer methods of the methanol extract prompted us to pursue further works on this extract. From the methanol extract of the stem bark of this plant, we have isolated one 
xanthone named 1-hydroxy-3,7,8-trimethoxyxanthone designated $\mathrm{AV}$ whose antiulcer properties are being reported here for the first time.

The present study is thus undertaken to determine the antiulcer potentials of 1-hydroxy-3,7,8-trimethoxyxanthone using three experimental models of gastric lesion induction namely, $\mathrm{HCl} /$ ethanol, Indometacin, and pylorus ligation.

\section{Materials and Methods}

2.1. Animals. The experiments were carried out on Wistar strain male adult rats, aged between 12 and 16 weeks and weighing between 170 and $200 \mathrm{~g}$. The rats were raised in the animal house of the Faculty of Science of the University of Dschang and fed normal laboratory rat diet with food and water given ad libitum. All animals used were starved for $48 \mathrm{~h}$ prior to use.

All procedures described in the present work as concern the use of experimental animals were in strict respect of the ethics regarding the use, the handling, and the preservation of the Cameroonian flora and fauna as specified by the Ministry of Forest and Wildlife and the Ministry of Scientific and Technical Research.

2.2. Plant Material. The stem bark of Anthocleista vogelii was collected in Bandjoun, in the West Province of Cameroon, during the month of May 2005. Mr. Paul Mesili, a retired botanist of the Cameroon herbarium, Yaoundé, carried out the authentication. A voucher specimen (BUD 0636) has been deposited at the Botany Department, University of Dschang.

2.3. Extraction and Isolation. The shade-dried stem bark of Anthocleista vogelii was ground into very fine powder in a high speed grinding mill.

The stem bark powder $(3000 \mathrm{~g})$ was soaked with $5 \mathrm{~L}$ of hexane for $72 \mathrm{~h}$. The filtrate was concentrated to dryness in a rotary evaporator under reduced pressure at a temperature of $35^{\circ} \mathrm{C}$ to give $31.6 \mathrm{~g}$ of hexane extract $(01.05 \%$ yield). The mark lifted was then macerated in $5 \mathrm{~L}$ of acetone for $72 \mathrm{~h}$, and the filtrate obtained was concentrated at a temperature of $30^{\circ} \mathrm{C}$ to give $112.3 \mathrm{~g}$ of acetone extract ( $03.74 \%$ yield). The mark lifted was further macerated in $5 \mathrm{~L}$ of methanol for $72 \mathrm{~h}$ and the filtrate was concentrated to dryness using reduced pressure at a temperature of $30^{\circ} \mathrm{C}$ using rotary evaporator to give $676 \mathrm{~g}$ of methanol extract ( $22.53 \%$ yield). This methanol extract was soluble in distilled water.

This methanol extract (100 g) was chromatographed on a silica gel column and elution performed with a gradient mixture of dichloromethane $\left(\mathrm{CH}_{2} \mathrm{Cl}_{2}\right)$-methanol. Sixty fractions of $250 \mathrm{~mL}$ each were collected and combined on the basis of their TLC profiles to give 10 major fractions numbered $F_{1}-$ $F_{10}$. Fraction 3 exhibited one major compound on TLC. The 10 fractions were tested for their antiulcerogenic properties. Standing at room temperature, fraction 3 gave a precipitate that was filtered to afford a crude crystal mixture. This crystal mixture underwent further purification on a silica gel column with the isocratic mixture $\left(\mathrm{CH}_{2} \mathrm{Cl}_{2}\right.$-methanol $\left.95: 5\right)$ to yield

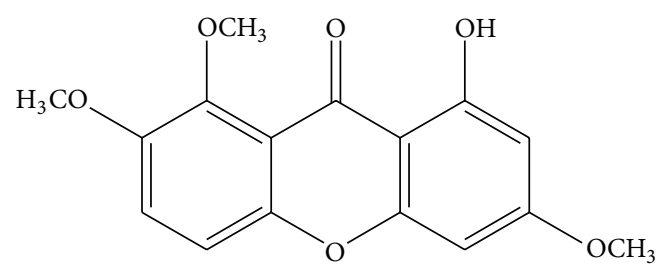

FIgURE 1: Structure of the xanthone 1-hydroxy-3,7,8-trimethoxyxanthone $\left(\mathrm{C}_{15} \mathrm{H}_{14} \mathrm{O}_{6}\right)$.

a yellow water soluble crystalline compound $(24 \mathrm{mg})$. With indications obtained from the TLC and melting point, the compound was identified in comparison to 1-hydroxy-3,7,8trimethoxyxanthone (AV) previously isolated from the same plant in our laboratory [8] (Figure 1). This compound was used as the main pure isolated principle in all our trials.

2.4. Chemicals. Indomethacin, $\mathrm{DMSO}, \mathrm{HCl} /$ ethanol, and $\mathrm{NaOH}$ were obtained from Sigma Chemicals, and Cimetidine (Tagamet) and Sucralfate (Ulcar) were obtained from a local pharmacy.

2.5. HCl/Ethanol-Induced Gastric Mucosal Lesions. Gastric mucosal lesions were induced in male rats using the $\mathrm{HCl}$ / ethanol method as described [9]. The animals were divided into 17 groups each consisting of 6 rats. Group 1 represented the negative control group, which received $1 \mathrm{~mL} / 100 \mathrm{~g}$ body weight distilled water. Groups 2, 3, and 4 represent the positive control groups which received $1 \mathrm{~mL} / 100 \mathrm{~g}$ body weight Cimetidine $(12 \mathrm{mg} / \mathrm{kg}$ ) and Sucralfate (50 and $100 \mathrm{mg} / \mathrm{kg}$ ) solutions, respectively. Groups 5 to 14 received also $1 \mathrm{~mL} / 100 \mathrm{~g}$ body weight fractions obtained at a single dose of $100 \mathrm{mg} / \mathrm{kg}$. Groups 15 to 17 received $1 \mathrm{~mL} / 100 \mathrm{~g}$ body weight $\mathrm{AV}$ at doses of 1,2 , and $5 \mathrm{mg} / \mathrm{kg}$. All test substances were administered orally. One hour after drug treatment, $1 \mathrm{~mL}$ per $150 \mathrm{~g}$ body weight of the necrotizing solution $(150 \mathrm{mM} \mathrm{HCl}$ in $60 \%$ ethanol) was given per os to each rat. The rats were sacrificed one hour later using an overdose of ether and the stomach removed and observed for ulcers in the glandular region. The surface area of each lesion was measured and scored as described [10]. The ulcer index for each rat was taken as the mean ulcer score (0: no ulcer; 1 : US $\leq 0,5 \mathrm{~mm}^{2} ; 2: 0,5 \mathrm{~mm}^{2}<$ $\mathrm{US} \leq 2,5 \mathrm{~mm}^{2} ; 3: 2,5 \mathrm{~mm}^{2}<\mathrm{US} \leq 5 \mathrm{~mm}^{2} ; 4: 5 \mathrm{~mm}^{2}<\mathrm{US} \leq$ $10 \mathrm{~mm}^{2}$; 5: $10 \mathrm{~mm}^{2}<\mathrm{US} \leq 15 \mathrm{~mm}^{2} ; 6: 15 \mathrm{~mm}^{2}<\mathrm{US} \leq$ $20 \mathrm{~mm}^{2} ; 7: 20 \mathrm{~mm}^{2}<\mathrm{US} \leq 25 \mathrm{~mm}^{2} ; 8: 25 \mathrm{~mm}^{2}<\mathrm{US} \leq$ $30 \mathrm{~mm}^{2} ; 9: 30 \mathrm{~mm}^{2}<\mathrm{US} \leq 35 \mathrm{~mm}^{2} ; 10: \mathrm{US}>35 \mathrm{~mm}^{2}$ ).

The percentage ulcerated surface was calculated as the total area covered by all lesions expressed as a proportion of the total corpus mucosal surface area. The percentage of inhibition $(\% I)$ was calculated using the following formula:

$$
\% I=\frac{(\mathrm{USc}-\mathrm{USt}) \cdot 100}{\mathrm{USc}}
$$

where USc $=$ ulcer surface area of control and USt $=$ ulcer surface area of test animal. 
2.6. Indometacin-Induced Ulcer. In order to ascertain whether the antiulcer properties of the compound were mediated by the stimulation of cyclooxygenase activity, the Indometacin-induced model was utilized as described [11]. Thirty male rats divided into 5 groups of 6 rats each were treated with increasing doses of AV ranging from 1 to $5 \mathrm{mg} /$ $\mathrm{kg}$, giving orally (po) each as a single dose.

The negative control group received distilled water, whereas the positive control group received Cimetidine $(12 \mathrm{mg} / \mathrm{kg})$. The animals received $1 \mathrm{~mL} / 100 \mathrm{~g}$ body weight distilled water, Cimetidine, or compound (AV). One hour after drug administration, each animal received orally $30 \mathrm{mg} / \mathrm{kg}$ of Indometacin. All animals were sacrificed five hours later by overdose of ether. The stomach was removed and examined for lesions in the glandular portion. The ulcers produced were scored using a modification of the method described [12]: 0 , absence of ulcer; 1 , vessel dilatation and pointed ulcers; 2.5 , small ulcers $<4 \mathrm{~mm}$ long; $3.5,4 \mathrm{~mm}$ long $\leq$ ulcers $\geq$ $5 \mathrm{~mm}$ long; 5, large ulcers $>5 \mathrm{~mm}$ long. The ulcer index and the percentage of inhibition were estimated as described above.

2.7. Pylorus-Ligated Secretion and Ulceration. This method was used to investigate the neutralizing properties and/or the antisecretory effects of AV. Thirty-six male rats divided into 6 groups of 6 rats each were given orally $1 \mathrm{~mL} / 100 \mathrm{~g}$ body weight of Cimetidine (12 mg/kg), Maalox (50 mg/kg), AV (1, 2, and $5 \mathrm{mg} / \mathrm{kg}$ ), or distilled water, respectively. One hour after the administration of different drugs, the pylorus of each rat was tied under light ether anesthesia and the abdominal incision was closed. Six hours after the ligation, the animals were sacrificed using overdose of ether and the stomach removed. A small nick was made at the junction of pylorus ligation and greater curvature. The contents of the stomach were collected in centrifuge tubes. The tubes were centrifuged at $3000 \mathrm{rpm}$ for $10 \mathrm{~min}$. The volume of supernatant fluid was measured and used for $\mathrm{pH}$ analysis. The stomach was opened along the greater curvature and ulcers produced were graded according to a modification of the method described [13]. The ulcer index and the percentage of inhibition were estimated as described above.

2.8. Measurement of Gastric Acidity. Total centrifuged gastric contents $(1 \mathrm{~mL})$ from each pylorus ligated rat were analysed for hydrogen ion concentration by titrating against a $0.01 \mathrm{~N}$ solution of $\mathrm{NaOH}$ using a $\mathrm{pH}$ meter (Suntex TS-2). The experiment was done in triplicate.

2.9. Measurement of Mucus Production. Gastric mucus production was measured in the rats subjected to $\mathrm{HCl} /$ ethanol, Indometacin, and pylorus ligation-induced lesions according to the method described [14]. The gastric mucosa of each rat was gently scraped using a glass slide, and the mucus obtained was carefully weighed using a sensitive digital electronic balance. The same experimenter performed this operation each time.
2.10. Statistical Analysis. Statistical analysis was performed using ANOVA and Student's $t$-test, and significance of difference between treatments was accepted at $P<0.05$. Data are expressed as mean \pm standard error of the mean.

\section{Results}

3.1. HCl/Ethanol-Induced Ulcer. The ten major fractions of the methanol extract of $A$. vogelii obtained by chromatography were tested at the dose of $100 \mathrm{mg} / \mathrm{kg}$ on gastric ulcers induced by $\mathrm{HCl} /$ ethanol. Except $F_{7}$, all the fractions tested induced a significant reduction in both ulcer surface area and mean ulcer index and significantly increased mucus weight compared with negative control group receiving distilled water. Fractions $F_{3}$ and $F_{9}$ showed very high percentage of inhibition (83.21 and 86.10, resp.).

The oral administration of the $\mathrm{HCl} /$ ethanol solution produced characteristic lesions in the glandular portion of the stomach of the negative control group of rats receiving distilled water with a total surface area of $132.61 \pm 24.70 \mathrm{~mm}^{2}$. The compound (AV) administered at the doses of 1,2 , and $5 \mathrm{mg} / \mathrm{kg}$ produced a significant $(P<0.01)$ decrease in ulcer surface area from $132.61 \pm 24.70 \mathrm{~mm}^{2}$ in the negative control group to $51.85 \pm 4.83,8.99 \pm 5.77$ and $14.62 \pm 1.27 \mathrm{~mm}^{2}$ in groups receiving 1,2 , and $5 \mathrm{mg} / \mathrm{kg}$ of $\mathrm{AV}$, leading to an inhibition percentage of $60.90,93.22$, and $88.98 \%$, respectively. The mean ulcer index score decreased significantly $(P<0.01)$ from $5.49 \pm 0.98$ in negative control group to $2.32 \pm 1.26$ and $2.86 \pm 0.30$ for rats receiving 2 and $5 \mathrm{mg} / \mathrm{kg}$ of AV, respectively, while the mucus weight significantly $(P<$ 0.01 ) increased from $51.00 \pm 0.46 \mathrm{mg}$ in the negative control group to $115.00 \pm 2.21$ and $90.00 \pm 1.13 \mathrm{mg}$, respectively, in animals treated with 2 and $5 \mathrm{mg} / \mathrm{kg}$ of AV. Animals treated with Cimetidine $(12 \mathrm{mg} / \mathrm{kg})$ produced an ulcer surface area of $92.82 \pm 16.62 \mathrm{~mm}^{2}$, corresponding to $29.84 \%$ inhibition, and Sucralfate produced a significant $(P<0.01)$ decrease in ulcer surface area from $132.61 \pm 24.70$ to $36.87 \pm 25.14 \mathrm{~mm}^{2}$ at the dose of $50 \mathrm{mg} / \mathrm{kg}$ and $25.21 \pm 4.26 \mathrm{~mm}^{2}$ at the dose of $100 \mathrm{mg} / \mathrm{kg}$, leading to an inhibition percentage of 72.20 and $80.99 \%$, respectively (Table 1 ).

3.2. Indometacin-Induced Gastric Lesions. Table 2 shows the results obtained when $\mathrm{AV}$ was used to prevent the formation of gastric lesions induced by Indomethacin. Oral administration of AV at the doses of 1,2 , and $5 \mathrm{mg} / \mathrm{kg}$ dose dependently significantly $(P<0.01)$ prevented the formation of gastric lesions induced by Indomethacin (46.86, 76.91, and $89.68 \%$ inhibition, resp.), leading to ulcer surface areas of $44.09 \pm$ $8.86,19.16 \pm 5.36$, and $8.56 \pm 5.64 \mathrm{~mm}^{2}$ compared to the negative control group receiving distilled water $(82.97 \pm$ $\left.5.08 \mathrm{~mm}^{2}\right)$. The mean ulcer index score significantly $(P<$ $0.05)$ decreased from $3.64 \pm 0.68$ in negative control animals to $3.00 \pm 0.45,2.83 \pm 0.84$, and $1.38 \pm 0.68$ for groups receiving 1,2 , and $5 \mathrm{mg} / \mathrm{kg}$ of AV.

The mucus weight of the negative control animals (57.00 \pm $0.64 \mathrm{mg})$ significantly $(P<0.01)$ increased to $79.00 \pm 1.00$ in animals receiving a dose of $5 \mathrm{mg} / \mathrm{kg}$ of AV. Sucralfate produced a significant $(P<0.01)$ reduction in ulcer surface 
TABLE 1: Effect of the ten fractions of the methanol extract of A. vogelii and 1-hydroxy 3,7,8-trimethoxyxanthone (AV) on $\mathrm{HCl} / \mathrm{ethanol}$-induced gastric lesions in rats.

\begin{tabular}{|c|c|c|c|c|c|c|c|}
\hline Treatment & $n$ & Dose $(\mathrm{mg} / \mathrm{kg})$ & US area $\left(\mathrm{mm}^{2}\right)$ & Ulcer index & $\%$ US & $\% I$ & Mucus weight (mg) \\
\hline Distilled water & 6 & - & $132.61 \pm 24.70$ & $5.49 \pm 0.98$ & 22.02 & - & $51.00 \pm 0.46$ \\
\hline Cimetidine & 6 & 12 & $92.82 \pm 16.62$ & $5.57 \pm 0.76$ & 13.78 & 29.84 & $61.00 \pm 0.83$ \\
\hline \multirow{2}{*}{ Sucralfate } & 6 & 50 & $36.87 \pm 25.14^{\mathrm{b}}$ & $3.46 \pm 1.75$ & 4.82 & 72.20 & $78.00 \pm 0.96^{\mathrm{b}}$ \\
\hline & 6 & 100 & $25.21 \pm 4.26^{\mathrm{b}}$ & $3.72 \pm 0.38^{\mathrm{a}}$ & 3.80 & 80.99 & $85.00 \pm 1.20^{\mathrm{b}}$ \\
\hline$F_{1}$ & 6 & 100 & $50.21 \pm 11.51^{\mathrm{b}}$ & $4.45 \pm 0.74$ & 6.11 & 61.51 & $100.00 \pm 3.79^{\mathrm{b}}$ \\
\hline$F_{2}$ & 6 & 100 & $48.12 \pm 11.04^{\mathrm{b}}$ & $3.89 \pm 0.46^{\mathrm{a}}$ & 6.59 & 63.71 & $98.00 \pm 4.62^{\mathrm{b}}$ \\
\hline$F_{3}$ & 6 & 100 & $22.27 \pm 15.20^{\mathrm{b}}$ & $2.83 \pm 1.39^{\mathrm{b}}$ & 3.18 & 83.21 & $116.00 \pm 7.89^{\mathrm{b}}$ \\
\hline$F_{4}$ & 6 & 100 & $38.61 \pm 16.82^{\mathrm{b}}$ & $3.07 \pm 0.72^{b}$ & 5.00 & 70.88 & $100.00 \pm 4.59^{\mathrm{b}}$ \\
\hline$F_{5}$ & 6 & 100 & $44.73 \pm 21.45^{\mathrm{b}}$ & $3.73 \pm 0.42^{b}$ & 5.71 & 66.27 & $95.00 \pm 2.60^{\mathrm{b}}$ \\
\hline$F_{6}$ & 6 & 100 & $29.40 \pm 14.37^{\mathrm{b}}$ & $3.09 \pm 0.31^{\mathrm{b}}$ & 3.84 & 77.84 & $104.00 \pm 5.62^{b}$ \\
\hline$F_{7}$ & 6 & 100 & $101.65 \pm 18.24$ & $5.28 \pm 0.77$ & 1.46 & 23.35 & $65.00 \pm 4.82$ \\
\hline$F_{8}$ & 6 & 100 & $36.19 \pm 17.05^{\mathrm{b}}$ & $3.52 \pm 0.68^{b}$ & 4.57 & 72.71 & $101.00 \pm 7.20^{b}$ \\
\hline$F_{9}$ & 6 & 100 & $18.43 \pm 6.43^{\mathrm{b}}$ & $3.10 \pm 0.63^{\mathrm{b}}$ & 2.47 & 86.10 & $106.00 \pm 6.05^{\mathrm{b}}$ \\
\hline$F_{10}$ & 6 & 100 & $50.90 \pm 17.50^{\mathrm{b}}$ & $3.58 \pm 0.47^{\mathrm{a}}$ & 6.41 & 61.62 & $88.00 \pm 4.39^{\mathrm{b}}$ \\
\hline AV & 6 & 1 & $51.85 \pm 4.83^{\mathrm{b}}$ & $4.87 \pm 0.80$ & 8.31 & 60.90 & $55.00 \pm 0.56$ \\
\hline AV & 6 & 2 & $8.99 \pm 5.77^{b}$ & $2.32 \pm 1.26^{\mathrm{b}}$ & 1.40 & 93.22 & $115.00 \pm 2.21^{b}$ \\
\hline AV & 6 & 5 & $14.62 \pm 1.27^{\mathrm{b}}$ & $2.86 \pm 0.30^{\mathrm{b}}$ & 2.22 & 88.98 & $90.00 \pm 1.13^{\mathrm{b}}$ \\
\hline
\end{tabular}

$N=$ number of rats per group.

$I=$ inhibition.

US $=$ ulcer surface.

${ }^{\mathrm{a}} \mathrm{P} \leq 0.05 ;{ }^{\mathrm{b}} \mathrm{P} \leq 0.01$ statistically significant relative to negative control (distilled water).

TABLE 2: Effects of 1-hydroxy-3,7,8-trimethoxyxanthone (AV) on gastric lesions induced by Indometacin in rat.

\begin{tabular}{lccccccc}
\hline Treatment & $n$ & Dose $(\mathrm{mg} / \mathrm{kg})$ & US area $\left(\mathrm{mm}^{2}\right)$ & Ulcer index & \% US & \% I & Mucus weight $(\mathrm{mg})$ \\
\hline Distilled water & 6 & - & $82.97 \pm 5.08$ & $3.64 \pm 0.68$ & 13.96 & - & $57 \pm 0.64$ \\
Sucralfate & 6 & 50 & $14.75 \pm 3.39^{\mathrm{b}}$ & $3.16 \pm 0.61$ & 02.43 & 82.22 & $59 \pm 0.40$ \\
AV & 6 & 1 & $44.09 \pm 8.86^{\mathrm{b}}$ & $3.00 \pm 0.45^{\mathrm{a}}$ & 07.49 & 46.86 & $58 \pm 0.35$ \\
AV & 6 & 2 & $19.16 \pm 5.36^{\mathrm{b}}$ & $2.83 \pm 0.84^{\mathrm{a}}$ & 03.05 & 76.91 & $62 \pm 0.72$ \\
AV & 6 & 5 & $8.56 \pm 5.64^{\mathrm{b}}$ & $1.38 \pm 0.68^{\mathrm{b}}$ & 01.30 & 89.68 & $79 \pm 1.00^{\mathrm{b}}$ \\
\hline
\end{tabular}

$N=$ number of rats per group.

$I=$ inhibition.

US $=$ ulcer surface.

${ }^{\mathrm{a}} P \leq 0.05 ;{ }^{\mathrm{b}} P \leq 0.01$ statistically significant relative to negative control (distilled water).

area from $82.97 \pm 5.08$ to $14.75 \pm 3.39 \mathrm{~mm}^{2}$ at the dose of $50 \mathrm{mg} / \mathrm{kg}$, leading to inhibition percentage of $82.22 \%$.

3.3. Pylorus Ligation-Induced Gastric Lesions. The results obtained when ulceration of the gastric mucosa was provoked by pylorus ligation are shown in Table 3. Pyloric ligation of rats in the negative control group produced pointed lesions or raised inflammation. The total ulcer surface area of the negative control group $\left(64.63 \pm 5.24 \mathrm{~mm}^{2}\right)$ was significantly $(P<0.01)$ decreased to $21.36 \pm 4.19$ and $18.94 \pm 3.65 \mathrm{~mm}^{2}$ when AV was administered at the doses of 2 and $5 \mathrm{mg} / \mathrm{kg}$, respectively, leading to an inhibition percentage of 66.95 and $70.69 \%$. AV produced a nonsignificant $(P>0.05)$ decrease of mean ulcer index with doses of 1,2 , and $5 \mathrm{mg} / \mathrm{kg}(3.19 \pm 0.41$, $2.59 \pm 0.70$, and $2.19 \pm 0.70$, resp.) compared to the negative control group (3.91 \pm 1.16$)$. Cimetidine at the dose of $12 \mathrm{mg} / \mathrm{kg}$ and Maalox at the dose of $50 \mathrm{mg} / \mathrm{kg}$ produced a significant $(P<0.01)$ decrease in surface area from $64.63 \pm 5.24 \mathrm{~mm}^{2}$ in the negative control animals to $41.45 \pm 8.43 \mathrm{~mm}^{2}$ in rats treated with Cimetidine and $24.15 \pm 2.88 \mathrm{~mm}^{2}$ in animals receiving Maalox, leading to inhibition percentage of 35.87 and $62.63 \%$, respectively. The volume of the gastric juice of the three groups of rats receiving AV was comparable to the negative control group while the gastric acidity of the negative control animals $(134.17 \pm 2.04 \mathrm{mEq} / \mathrm{l})$ was significantly $(P<$ 0.05 ) reduced to $96.93 \pm 25.39 \mathrm{mEq} / \mathrm{l}$ in the group receiving $5 \mathrm{mg} / \mathrm{kg}$ of AV. The mucus weight of the negative control group $(56.00 \pm 0.69 \mathrm{mg})$ significantly $(P<0.01)$ increased to $79.00 \pm 0.48$ and $78.00 \pm 0.40$ when $\mathrm{AV}$ was administered at doses of 2 and $5 \mathrm{mg} / \mathrm{kg}$.

\section{Discussion}

The antiulcer methods were selected in order to test AV for gastric cytoprotective and antisecretory activities. Oral administration of the compound at the doses of 2 and $5 \mathrm{mg} / \mathrm{kg}$ 
TABLE 3: Effects of 1-hydroxy-3,7,8-trimethoxyxanthone (AV) on pylorus ligation ulceration.

\begin{tabular}{lcccccccccc}
\hline Treatment & $n$ & $\begin{array}{c}\text { Dose } \\
(\mathrm{mg} / \mathrm{kg})\end{array}$ & $\begin{array}{c}\text { US area } \\
\left(\mathrm{mm}^{2}\right)\end{array}$ & Ulcer index & $\%$ US & $\% I$ & Gastric juice $(\mathrm{mL})$ & Gastric PH & $\begin{array}{c}\text { Gastric acidity } \\
(\mathrm{mEq} / \mathrm{L})\end{array}$ & $\begin{array}{c}\text { Mucus } \\
\text { weight }(\mathrm{mg})\end{array}$ \\
\hline Distilled water & 6 & - & $64.63 \pm 5.24$ & $3.91 \pm 1.16$ & 16.62 & - & $5.71 \pm 0.71$ & $1.83 \pm 0.66$ & $134.17 \pm 2.04$ & $56.00 \pm 0.69$ \\
Cimetidine & 6 & 12 & $41.45 \pm 8.43^{\mathrm{b}}$ & $2.33 \pm 0.34$ & 06.52 & 35.87 & $5.53 \pm 0.79$ & $1.58 \pm 0.93$ & $89.95 \pm 19.71^{\mathrm{b}}$ & $63.00 \pm 0.60$ \\
Maalox & 6 & 50 & $24.15 \pm 2.88^{\mathrm{b}}$ & $2.72 \pm 0.28$ & 03.71 & 62.63 & $6.30 \pm 0.63^{\mathrm{b}}$ & $0.97 \pm 0.34^{\mathrm{a}}$ & $115.55 \pm 26.13$ & $64.00 \pm 0.66$ \\
AV & 6 & 1 & $68.34 \pm 4.32$ & $3.19 \pm 0.41$ & 12.21 & 0.00 & $4.51 \pm 1.18$ & $1.80 \pm 1.03$ & $118.55 \pm 51.76$ & $58.00 \pm 0.66$ \\
AV & 6 & 2 & $21.36 \pm 4.19^{\mathrm{b}}$ & $2.59 \pm 0.70$ & 04.08 & 66.95 & $5.70 \pm 1.88$ & $1.08 \pm 0.14^{\mathrm{a}}$ & $121.50 \pm 30.50$ & $79.00 \pm 0.48^{\mathrm{b}}$ \\
AV & 6 & 5 & $18.94 \pm 3.65^{\mathrm{b}}$ & $2.19 \pm 0.70$ & 03.44 & 70.69 & $4.88 \pm 0.90$ & $1.49 \pm 0.54$ & $96.93 \pm 25.39^{\mathrm{a}}$ & $78.00 \pm 0.40^{\mathrm{b}}$ \\
\hline
\end{tabular}

$N=$ number of rats per group.

$I=$ inhibition.

US $=$ ulcer surface.

${ }^{\mathrm{a}} P \leq 0.05{ }^{\mathrm{b}} P \leq 0.01$ statistically significant relative to negative control (distilled water).

to rats significantly $(P<0.01)$ prevented the formation of gastric lesions induced by $\mathrm{HCl} /$ ethanol, Indometacin, and pylorus ligation.

The gastric cytoprotective effect of the compound in $\mathrm{HCl} /$ ethanol treated model is related to an effect other than the simple neutralization of the acid in the necrotizing mixture. This gastric mucosal protection against $\mathrm{HCl} /$ ethanol can be mediated by enhanced gastric mucosal defence through increasing mucus and/or bicarbonate production or reducing the volume of gastric acid secretion by the parietal cells [15]. The antiulcer activity of AV could thus be mediated through one of these numerous pathways.

To probe the possible mechanisms of action of $\mathrm{AV}$, their antiulcer potency was tested against Indometacin. The results obtained show that $\mathrm{AV}$ at the dose of $5 \mathrm{mg} / \mathrm{kg}$ significantly $(P<0.01)$ reduced the ulcer surface area and the mean ulcer index while the mucus weight significantly $(P<0.01)$ increased. Treatment with Indometacin causes gastric mucosal injury through a reduction of endogenous prostaglandin biosynthesis, inhibition of gastroduodenal bicarbonate secretion, and disruption of the mucosal barrier. Prostaglandins promote mucus secretion and play an important role in maintaining mucosal integrity against the actions of various damaging agents [16-18]. AV significantly $(P<$ 0.01 ) inhibited ulcer surface area in all experimental models and increased the mucus weight which became significant $(P<0.01)$ at the dose of $5 \mathrm{mg} / \mathrm{kg}$ compared with the negative control group. It can then be thought that the cytoprotective effect of the compound results from the enhancement of the mucosal barrier through the increased production of prostaglandin or from a direct mucosal protection similar to that of prostaglandin as suggested $[19,20]$ when interpreting similar results.

The ability of the compound to inhibit gastric acid secretion was tested against pylorus ligation-induced gastric lesions. This method demonstrated the antiulcer effect of AV with 66.95 and $70.69 \%$ inhibition of ulcer formation at the doses of 2 and $5 \mathrm{mg} / \mathrm{kg}$ accompanied by a significant $(P<$ 0.05 ) increase of mucus production (79 and $78 \mathrm{mg}$ ) at the same doses. Gastric acidity of the negative control animals $(134.17 \pm 2.04 \mathrm{mE} / \mathrm{l})$ was significantly $(P<0.05)$ reduced to $96.93 \pm 25.39 \mathrm{mE} / \mathrm{l}$ in the group receiving $5 \mathrm{mg} / \mathrm{kg}$ of $\mathrm{AV}$ but was still higher to provoke ulcer in the normal conditions.
This reduction in gastric acidity compared to the percentage of inhibition and to the mucus weight obtained suggests that the cytoprotective action of AV through an antisecretory effect may be secondary to a possible direct mucosal protection against mucosal autodigestion.

\section{Conclusion}

Our results suggest that the compound taken orally in experimental ulcer models has cytoprotective properties which may explain the clinical effect of the stem bark of Anthocleista vogelii when employed in ethnomedicine for the management of complaints which are symptomatic of peptic ulcer disease. These effects are likely due to the ability of the compound to strengthen gastric mucosal defence through enhanced mucus production. AV appears to be a useful compound for the development of new antiulcer drugs and its toxicity profile and detailed mechanism of action await further studies.

\section{Conflict of Interests}

The authors declare that there is no conflict of interests regarding the publication of this paper.

\section{Acknowledgment}

The authors acknowledge, with thanks, the financial assistance of IPICS SWEDEN through the Project CAM 02.

\section{References}

[1] R. S. Cotran, V. Kumar, and S. L. Robbins, Robbins Pathologic Basis of Disease, Saunders, Philadelphia, Pa, USA, 4th edition, 1989.

[2] C. V. Rao, S. K. Ojha, K. Radhakrishnan et al., "Antiulcer activity of Utleria salicifolia rhizome extract," Journal of Ethnopharmacology, vol. 91, no. 2-3, pp. 243-249, 2004.

[3] P. V. Tan, C. K. Njimi, and J. F. Ayafor, "Screening of some African medicinal plants for antiulcerogenic activity: part 1," Phytotherapy Research, vol. 11, pp. 45-47, 1997.

[4] R. K. Goel and K. Sairam, "Anti-ulcer drugs from indigenous sources with emphasis on Musa sapientum, Tamrabhasma, 
Asparagus racemosus and Zingiber officinale," Indian Journal of Pharmacology, vol. 34, no. 2, pp. 100-110, 2002.

[5] G. Ateufack, T. Nguelefack, H. Wabo, P. Watcho, P. Tane, and A. Kamanyi, "Antiulcer effects of the aqueous and organic extracts of the stem bark of Anthocleista vogelii in rats," Pharmaceutical Biology, vol. 44, no. 3, pp. 166-171, 2006.

[6] J. M. Dalziel, The Useful Plants of West Tropical Africa, Crown Agents for the Colonies, London, UK, 1955.

[7] F. R. Irvine, Woody Plants of Ghana, Oxford University Press, London, UK, 1961.

[8] J. P. Chapelle, "Vogeloside and secologanic acid, secoiridoid glucosides from Anthocleista vogelii," Planta Medica, vol. 29, no. 3, pp. 268-274, 1976.

[9] D. A. Okorie, "A new phthalide and xanthones from Anthocleista djalonensis and Anthocleista vogelli," Phytochemistry, vol. 15, no. 11, pp. 1799-1800, 1976.

[10] M. Tene, P. Tane, J.-R. Kuiate, J. D. D. Tamokou, and J. D. Connolly, "Anthocleistenolide, a new rearranged nor-secoiridoid derivative from the stem bark of Anthocleista vogelii," Planta Medica, vol. 74, no. 1, pp. 80-83, 2008.

[11] N. Hara and S. Okabe, "Effects of gefarnate on acute gastric lesions in rats," Folia Pharmacologica Japonica, vol. 85, no. 6, pp. 443-446, 1985.

[12] T. A. Miller, "Protective effects of prostaglandins against gastric mucosal damage: current knowledge and proposed mechanisms," The American Journal of Physiology-Gastrointestinal and Liver Physiology, vol. 245, no. 5, part 1, pp. G601-G623, 1983.

[13] P. V. - Tan, E. I. Lyonga, G. N. Nditafon, C. K. Njimi, and M. Bopelet, "Gastric cytoprotective antiulcerogenic actions of the aqueous bark extract of Voacanga africana and leaf extract of Eremomastax speciosa in rats," Cameroonian Journal of Biological and Biochemical Sciences, vol. 7, pp. 69-77, 1997.

[14] A. K. Ganguly, "A method for quantitative assessment of experimentally produced ulcers in the stomach of albino rats," Experientia, vol. 25, no. 11, pp. 1224-1225, 1969.

[15] P. V. Tan and B. Nyasse, "Anti-ulcer compound from Voacanga africana with possible histamine $\mathrm{H}_{2}$ receptor blocking activity," Phytomedicine, vol. 7, no. 6, pp. 509-515, 2000.

[16] Y. Raji, I. A. Ogunwande, C. A. Osadebe, and G. John, "Effects of Azadirachta indica extract on gastric ulceration and acid secretion in rats," Journal of Ethnopharmacology, vol. 90, no. 1, pp. 167-170, 2004.

[17] B. J. R. Whittle, "Mechanisms underlying gastric mucosal damage induced by indomethacin and bile salts, and the actions of prostaglandins," British Journal of Pharmacology, vol. 60, no. 3, pp. 455-460, 1977.

[18] G. Flemstrom, A. Garner, and O. Nylander, "Surface epithelial $\mathrm{HCO}_{3}$ transport by mammalian duodenum in vivo," The American Journal of Physiology-Gastrointestinal and Liver Physiology, vol. 6, no. 5, pp. G348-G358, 1982.

[19] K. Yamamoto, H. Kakegawa, H. Ueda et al., "Gastric cytoprotective anti-ulcerogenic actions of hydroxychalcones in rats," Planta Medica, vol. 58, no. 5, pp. 389-393, 1992.

[20] X. B. Sun, T. Matsumoto, and H. Yamada, "Anti-ulcer activity and mode of action of the polysaccharide fraction from the leaves of Panax ginseng," Planta Medica, vol. 58, no. 5, pp. 432435, 1992. 


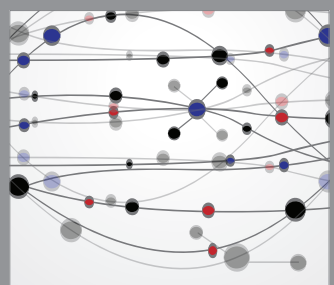

The Scientific World Journal
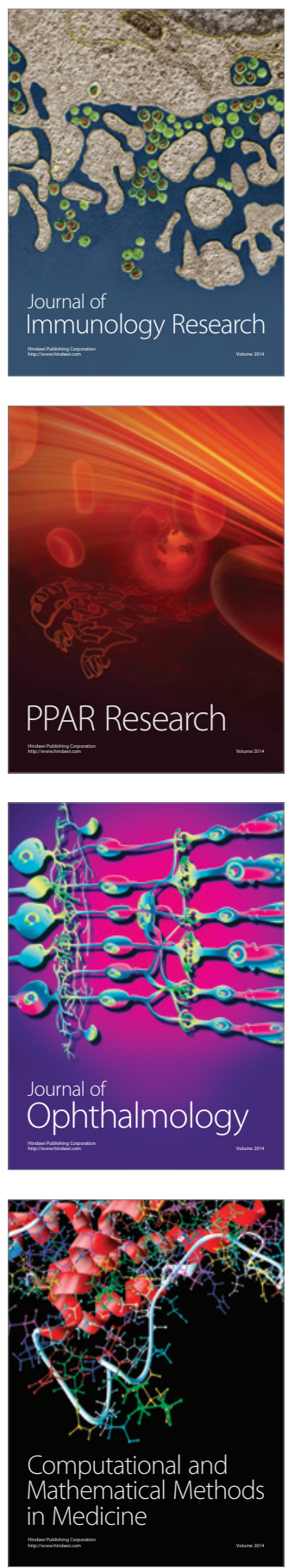

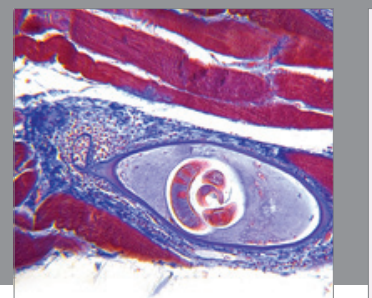

Gastroenterology

Research and Practice
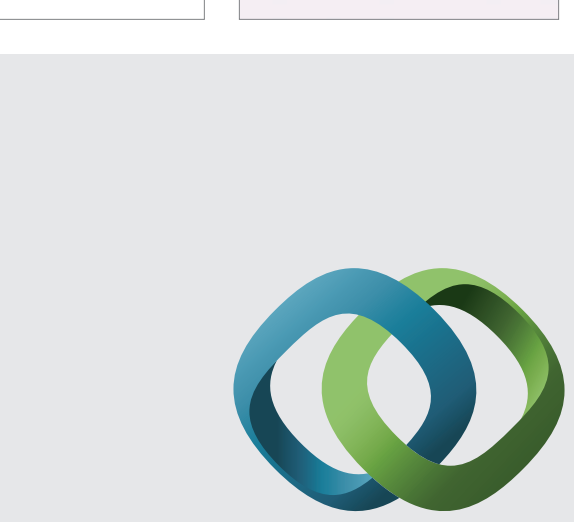

\section{Hindawi}

Submit your manuscripts at

http://www.hindawi.com
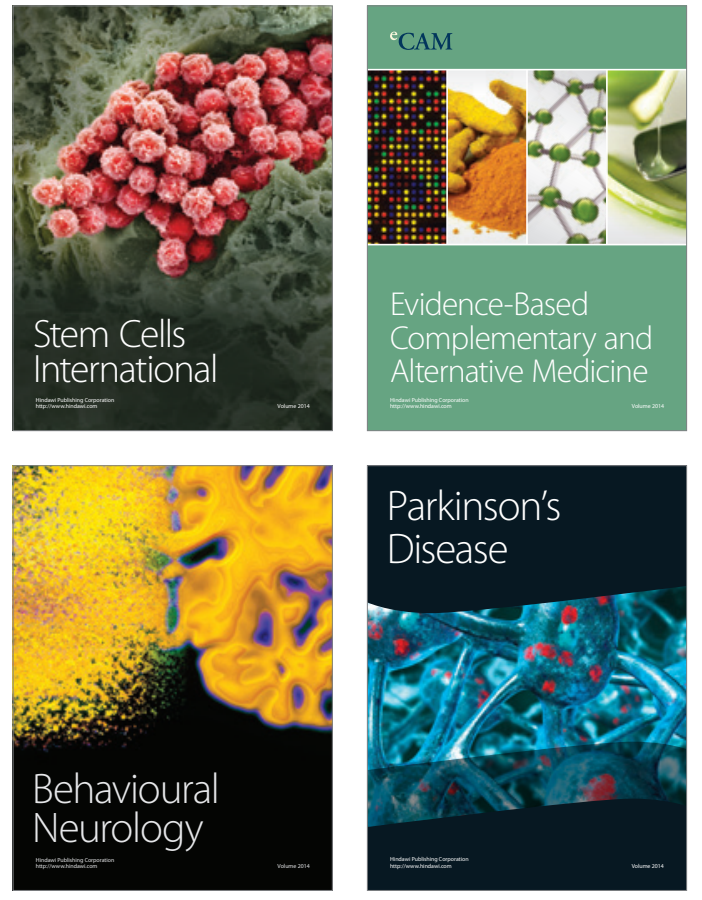
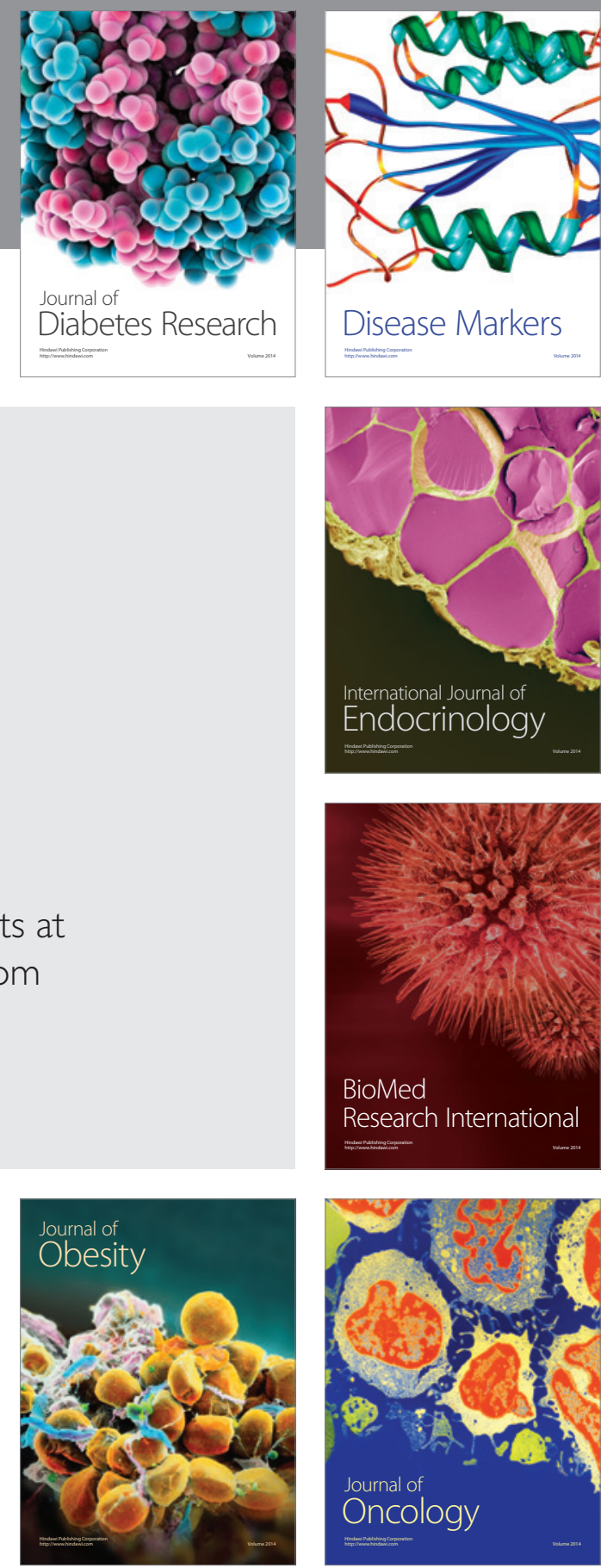

Disease Markers
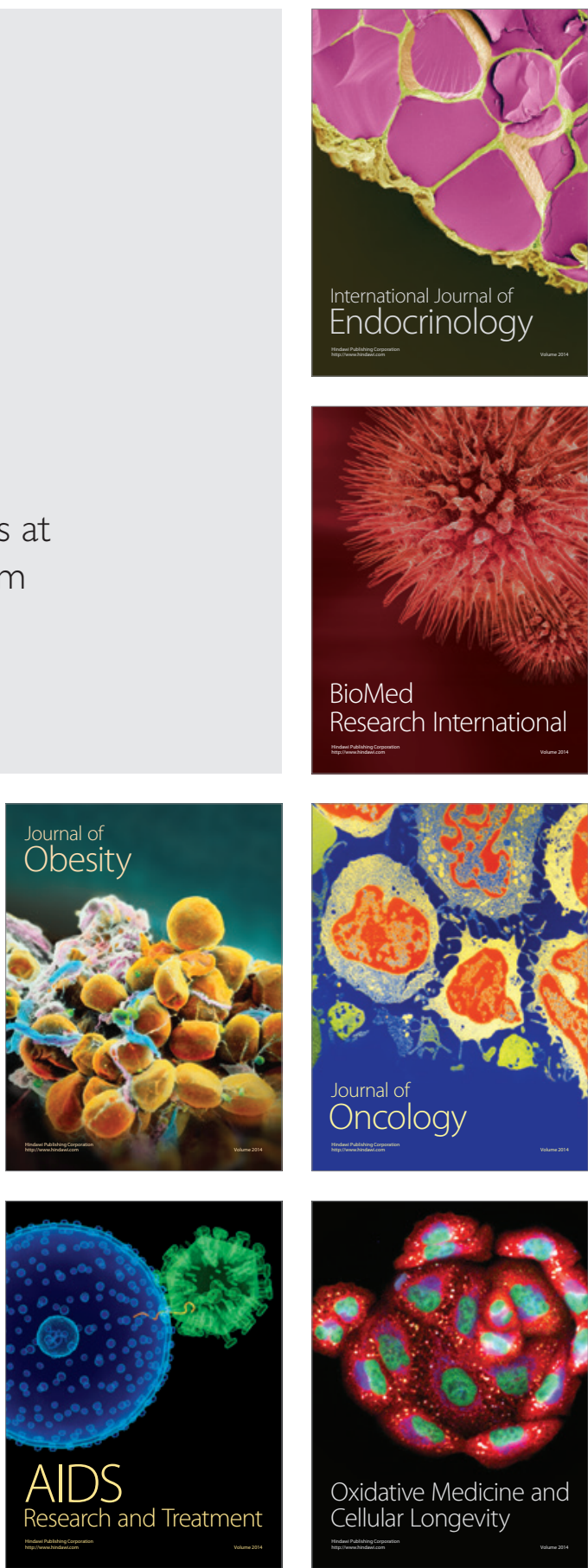